Semina $\square \quad \mathrm{Nr} 15$

Scientiarum 2016

s. $64-76$

DOI: http://dx.doi.org/10.15633/ss.1768

Anna Sarosiek

\title{
New technologies as prosthesis of cognitive system
}

In everyday life, each person uses a huge amount of tools. People, however, often do not realise this. The human cognitive system is a flexible mechanism - it is always ready for expansion. Humans not only gain new skills, but also demonstrate outstanding ability to use every new tools. Rapidly developing technologies provide humans with access to new utensils. These modern artefacts are often only the case or interface of technological developments. Interestingly, however, tools become an extension of the human mind. Humans examine the world with the help of artefacts. The artefacts allow them to interact with the surrounding reality. They also provide preprocessed data. All of this forms human development. The flexible cognitive mechanisms are based on the preprocessed data. They make it possible for individuals to acquire new skills. These present artefacts are often only the case or interface that is hiding the complicated processing programme. It is interesting to see how they become an extension of the human mind: they get a type of prosthesis, through which humans examine the world. Artefacts allow humans to interact with the surrounding reality. Through the flexibility of cognitive mechanisms and based on the data provided by tools, humans gain new skills. Tools, thus, become an integral part of the human cognitive system. There is no possibility of existing without them in the world. 
This paper was largely inspired by the research on the extended mind by Andy Clark. In particular, in the book Natural-born cyborgs: Minds, technologies, and the future of human intelligence ${ }^{1}$ Clark shows very quaint and encouraging research direction into the potential of the human cognitive system.

\section{The data processing and the cognition}

The cognitive system is, in a broadest sense, a cognitive activity of the mind. It has a specific organisation and it allows to define the functions and the modes of an action. This makes it possible to study the cognitive system as an organised structure - a set of mechanisms. Cognitive system is gathering and storing the knowledge of the environment in order to use it later to an action. It uses mental representations for this purpose, which are shaped in the processes of cognition. ${ }^{2}$ Therefore, human cognitive system is an information processing system. Psychologists use the contemporary methodology in their research on the accurate measurements of the phenomena occurring during information processing by a living organism. They used, for this purpose, traditional psychological tests, chronometric research as well as psychophysiological and technologically advanced tools for neuroimaging.

Characterizing a cognitive system is possible through using the above methods and identify the following: which information is input data; which procedures are used for the data processing; which structures are involved during the process, and, finally; as a result of these actions, which cognitive mechanism arises. ${ }^{3}$ The problem solving is related to the information process and precedes the execution of any task. This applies even to the simplest, and frequently

\footnotetext{
A. Clark, Natural-born cyborgs. Minds, technologies, and the future of human intelligence, New York 2004.

2 E. Nęcka, J. Orzechowski, B. Szymura, Psychologia poznawcza, Warszawa 2013.

3 L. Cosmides, J. Tooby, Cognitive adaptations for social exchange, "The Adapted Mind" 1992, pp. 163-228.
} 
beyond the control of human, activities such as seeing or mobility. The complex and precise analysis of data is an essential part of the processes of thinking, reasoning, deduction and decision-making. Operations of the cognitive system are based on neurobiological processes in the brain. They do not, however, take place either in the isolation of the experience of the body or without impacting the environment.

According to the latest surveys, the condition of proper information treatment is the embodiment. This means that the activity of mind depends on the brain as well as on the functioning of the body in which it is placed. One of the functons of the body is to provide data, which is received through the sense organs from the external and the internal environment. Methods of the cognitive psychology allow exploring the transformation of stimuli by both the body and the human mind (as well as any other living organism). Another assumption here is that the sensual body is used to data processing and the mind receives information which is partially preprocessed. Subsequently, the body exhibits a remarkable influence on mental processes.

\section{Tools in the role of prosthesis in the cognitive system}

In the ancient times and in the present, human inventions modified the way a man understands the world. The tools changed methods of human functioning in his environment. They transformed and defined the perspective of the perception problems. Homo habilis (handy man) started to use tools. This enabled him to hunt and gain meat. It is widely accepted to assume that this diet resulted in a rapid development of the human species. This example demonstrates that tools give new opportunities but they also put up new challenges. The man demanded them to be more efficient. Over time, new and strange external tools become an integral part of the human cognitive system as they enhanced problem solving. Technology supplemented the biological status of the man with the ability to create new connections between the mind and the uten- 
sils. These links became new patterns of mutual and causal dependencies. Tasks can be performed differently than before by using artefacts. The execution of the action depended extremely on information preprocessed (at least partially) by the tool. Human intelligence developed by using the achievements of science. The tools provided coevolutionary feedback and, thus, newer forms of adapting to the environment were formed.

David J. Bolter argues that "product changes its producer." ${ }_{4}$ The tool, such as prosthesis, becomes the cause of the modification of human interaction with the environment. New tools provide the easier and more effective functioning. At the same time, previous operating modes become time-consuming, exhausting and bring much less profit. Moreover, the natural human abilities are replaced with more accurate and more accessible data from the tools. Often, they allow the examination of the surrounding environment in a way that was previously unavailable. Thus, instruments began to serve as the external prosthesis. Functioning without them becomes hard or uneconomical or simply exhausting. The modified human activity rapidly displaces older models of action. It is transmitted to descendants and provide the continuous development as well as different ways of perceiving the reality.

One of the tools that affected the functioning of a man in the world was the invention of writing. The creation of this utility changed the perception of using a language. Until that time, the language was the way to communicate with others and the source of memory. The transmission of the history and the education took place by the oral communication. Written language represented also symbolic references to the meanings which were hidden behind the sounds. Therefore, it could be a magic power - capable of manipulating the nature or other people. Sometimes, it is treated as a divine gift. The invention of writing changed the language into a useful tool. The creation of writing altered the modus operandi of human memory. So far, the memory was continuously practiced and the formation of writ-

4 J. D. Bolter, Człowiek Turinga: kultura Zachodu w wieku komputera, tłum. T. Goban-Klas, Warszawa 1990, p. 308. 
ing changed this condition irrevocably. Anything could be verbally communicateda dn it could also be saved. Thus, memory training lost its validity, and human memory began to be based on notations; the writing became memory prosthesis.

The language began to be considered instrumentally. Words started to be perceived by both the sense of hearing and the sense of sight. As a result, people began to treat words as symbols, which are generating ideas in the human mind. That turned their ephemeral existence into more tangible and open to be developed and processed. Since then, a written text has been viewed as a structure which can be analysed and examined. This approach isolated a linguistic sign from its own denotation. ${ }^{5}$ The next step was the emergence of logic - very close to mathematics. The logic has changed both the method of language using and paradigm of its study. The belief that thoughts may be reduced to the language and then expressed in abstract logic symbols is ever-present since the Leibniz works. Language become the tool of percepting the world. The stating its syntactic structure was the major reason to treat it computationally. The human mental processes were thereafter defined as computational processes on the structure of mental representations. ${ }^{6}$

Language was able to change the cognitive landscape of the world. Using symbols could transform higher order task into simple tasks of the first order or to deliberate their identity or difference. The development of language as an external communication prosthesis was continued. The mathematical treatment of the language became decisive when computers appeared. In programming processes, an opportunity emerged to submit an instruction in a modified language understood by both humans and artefacts. Nowadays, we can communicate with machines, which transform the language into the symbolic structure and interpret it. The possibility of collaborating by a human and an artificial system is the crucial issue

J. D. Bolter, Człowiek Turinga..., op. cit., pp. 201-203.

6 J. A. Fodor, Eksperci od wiqzów. Język myśleński i jego semantyka, tłum. M. Gokieli, Warszawa 2001, p. 18. 
today. Man operating with environment can use every single machine as the tool.

There is no new habitat of human. The simplest technology changed the cognitive abilities of human as well. The oldest civilisations, for example, functioned without clocks. Sunrises and sunsets opened and closed cycles of human activity. The sense of the passing of the day or the night was depended on the subjective human perception. Thus, there was no reason to verify and update the space-time status. The time measuring appeared to be very rare and due only to exceptional circumstances. In addition, it was firmly vague and subjective. ${ }^{7}$ This state was changed by the clock invention. It meant that people began to count down the time dedicated to the work and the rest. The reflections of the time understood as a specific numerical values appeared. Time has become something that could be counted - a valuable commodity.

Thus, the new awareness of progress in time and time restrictions was formed. Clockwise moving began to involve every aspect of human activity, as well as the development of science. Every action started and finished under pressure of measured time. Today, time is of paramount importance. Previously, unknown concepts for the creation of culture have become indispensable. The time has a constant value, not only occasional references. The meaning of the measured time started taking nearly caricatural form, as the concept of man-hours: the amount of work done by a man in a certain unit of time. The widespread availability of clocks caused the need for the constant monitoring of each manifestation of the human activity. Everyone who wanted to be a part of a properly functioning society had to deal with the rigours of metered hours and minutes.

Thanks to the ability of the precise time calculation the development in physics could progress. It changied the human cosmological perspective. The ancients perceived the world as a timeless and immutable where the passing was reported only by the conviction of repeated cycles. The moderns require temporal limits. The concept of the infinite has become a serious problem for physicists

7 J. D. Bolter, Człowiek Turinga..., op. cit., p. 165. 
and programmers to address. Things once seen as eternity, currently became an error that needs to be fixed either by pointing out where the boundaries of time are or by finding a condition of terminating the computer program. ${ }^{8}$ Thus, the clock - prosthesis formalizing the passing - changed the human perception of the world.

\section{The influence of the technological development on the cognitive system}

The technological revolution in the 20th and early 21th centuries brought not only enormous changes in technology but also it allowed the application of new artefacts to each average man. Personal computers, mobile phones, commonly existing vending machines have become elements of the natural environment of humans. Most prevalent machines can be found in almost every home. Home computers connected to the international network can gain all the needed information within seconds. This is a new multi-level model of medium. The computer replaces the erstwhile erstwhile master. It allows gathering of information in a quick and attractive manner based on the interaction of video, audio and the system of references. Home computers transmit also ready reviews and opinions, update and modify the knowledge about the world. Most of all, computers affect the behaviour of their users, by presenting popular models of demeanour. This is extraordinary cognitive prosthesis probed the outer world. Computers are selecting the specific information, shaping the behaviour and influencing the user decision-making. They also provide access to social networking sites and programs enabling contact with an unlimited number of other users, replacing the natural relations with other people.

Thereby, the social activity of the user is modified. Employing the device, he tries to convey his thoughts as also his emotions. This kind of interaction with other people allows to understand and find therein all aspects of communication with another man. The ubiq-

8 J. D. Bolter, Człowiek Turinga..., op. cit., pp. 186-187. 
uitous Internet, as the Radoslaw Zyzik argued, has a significant influence on the functioning of the human mind. It creates new emotions, which formerly were not entitled to exist. ${ }^{9}$ These emotions are a blend of basic emotions which are well-known in psychology. They are formed as a result of new situations which meet the active user in a virtual environment. According to the modern psychology, emotions are adaptations regulating human way of thinking and his behaviour. They were developed to help solve problems and optimize decision-making processes. ${ }^{10}$ As a result of these reflections, it can be stated that the computer can be defined not only as a physical object, or a useful tool, but also as a symbiotic external cognitive system. It can model and simulate certain cognitive functions which, under different conditions, would require a laborious and timeless activity.

Also simpler digital devices like mobile phones, GPS, tablets and so on, have a substantial impact on cognitive processes. They help its user to orient himself in space and time. They allow the modern man to maintain full mobility, without losing contact with others and without feeling a lack of knowledge about the place that it considers its immediate environment. These tools help make everyday tasks. They provide the necessary data and information. Thanks to tools, the cognitive processes such as the time management, counting, acquiring the instantly required knowledge or finding the way can take place more quickly. Also, the need of troublesome searching or testing environment is eliminated. On the other hand, machines deployed in urbanized sites are ending the need for cooperation between individuals. They exclude the natural time-consuming and effort within interactions with other people. Additionally, they allow to acquire the knowledge or the wealth which are essential to function in common public areas.

Human comes into increasingly deep relationships with the technology. People use external prostheses to explore the world as well

9 R. Zyzik, Emocje 2.0, http://www.granicenauki.pl/index.php/pl/granice-nauki/ umysl/436-emocje-20 (3.01.2014).

10 R. Zyzik, Emocje 2.0, op. cit. 
as decide to place artificial parts inside their body. Cardiac pacemakers, endoprosthesis or cochlear implants do not astonish anyone. The interference with the body or substitution of natural organs is found valuable, especially if it allows to recover health or lost body functions. The technology has permission to create new tools cooperating with the human brain. Moreover, prosthesis are connected with human body deeper and deeper. There are also hi-tech prosthetic limbs; for example the chip in the retina can regain the vision. Replacing a missing biological organ allows to operate properly. It also demonstrates that modern implements permit to establish or to regain the contact with the world. Many of prosthesis becomes indispensable in order to exist in a full-fledged manner.

\section{The extended mind and its prosthesis}

Andy Clark, in his book Natural-born cyborgs, says that people are basically cyborgs. It should be pointed out that the image of the cyborg is a metaphor and has nothing in common with futuristic scenarios. ${ }^{11}$ Clark wants to emphasize that man has a natural predisposition to expand cognitive systems to tools. Over the centuries, starting with the first gain skills in using instruments, people are making cognitive revolutions by expanding the architecture mind to external devices. ${ }^{12}$ Clark considers the human mind in the interaction between the material brain and the body and the technological environment. Not only in terms of symbiotic connection to external devices, but by thinking and reasoning systems that connect biological brain circuits and nonbiological interfaces. In this approach, each human being that operates tools is a cyborg - to a greater or lesser degree. The human ability of the mind expanding with the associated external prostheses makes him increasingly smarter and more efficient. Man uses technology achievements to change his life.

11 E.g., this kind of futuristic view is the technological singularity known for the scenario of Raymond Kurzweil.

12 A. Clark, Natural-born cyborgs..., op. cit., p. 4. 
A lot of the daily routine is transferred to external devices. Thereby, cognitive processes are expanded to the external data repositories, which are currently available. Prostheses update data about the world on an ongoing basis as well as enabling the user to update. The human mind is linked to the world by relationship that refers to external objects and events. The skill to connect to biological and technological items makes human mind unique and different from other animals. ${ }^{13}$

Biological and technological systems are working together in order to minimize problems associated with the cognition. The external scaffolding relieves the human cognitive system and minimize energy-consuming calculations. The perception of living organisms is constantly based on them. This scaffolding consists of a relatively stable regularities in the environment. ${ }^{14}$ It means a human has no need to create detailed maps of the psychological or mental representations. He uses available and actual objects as the best models of the world. For humans, significant parts of the scaffoldings are made up of institutions of culture, language and technology. Scaffoldings are components of the world that can be used to relieve the cognitive system. A notepad, text files on the computer or pictures in a smartphone become a real part of the user memory.

It would appear, therefore, there is nothing extraordinary about every external device since they are simply tools of the cognitive equipment. The cognitive flexibility of the system is a natural phenomenon. ${ }^{15}$ The mechanisms of mind are designed to react with non-biological requisites. This capability enhances cognitive system by giving valuable knowledge on how to quickly and effectively retrieve information sufficient to know. External prostheses are aspects of thinking processes. They have access to outer data repositories. They have likewise the ability to transform a sense of self, feelings of being in a particular place and affect the operation.

13 A. Clark, Natural-born cyborgs..., op. cit., p. 7.

14 A. Clark, Being there: putting brain, body, and world together again, Cambridge 1997, pp. 32-33.

15 A. Clark, Natural-born cyborgs..., op. cit., p. 85. 
Prothesis extend human mental abilities; through them he recognize patterns, memorizes, adapts, predicts and perform the duties. They influence who is a man and where he is.

There is a real problem with testing the extended cognitive system. It cannot be considered independently of the human brain and body. Such methods would have to focus on the psychological effect of cognitive factors connected with the devices. This part of mind would not be isolated neither from person nor from the context. Another problem is, in the context of this idea, human cognition seems to be based partly on thoughtless actions. Clark describes the extended human mind as a part of a wide system. Part of it is build by external objects acting independently of a man. Without a doubt, Clark is going too far with his hypothesis. Boundaries of being a person, determined by its mind and body, are significantly exceeded. It is more correct to treat the tools as prosthesis rather than an integral part of the mind. That excluded the problematic issue of considering the outer part of human mind.

An unquestionable advantage of this theory is to direct attention to ways of using external objects to the expansion of the human cognitive system. Prosthesis are used to build a multi-layered database that can be stored in the mind, as well as in external storage devices. It strongly underlines the human potential in developing practical situated intelligence. A significant fact is that the functioning without these tools is increasingly difficult for contemporary people. Losing any of them does not remain meaningless. On the contrary, it results in a sense of losing something important. The absence of prostheses (such as mobile phone, text editing program or Internet access) causes that a man ceases to update himself. He knows and understands less than others and is left behind.

\section{Discussion and conclusions}

The continuous development of new technologies allows functioning in the world to people exposed by their disability to exclusion from the society. Invalid people, blind, hearing impaired or with 
mental disabilities have to look for alternative ways to operate effectively in an environment. A substitute sensory, like the invention of Paul Bach-y-Rita, allows blind people to perceive the environment through other sensory stimuli. ${ }^{16}$ Controlled by brain waves actuators partially restore paralysed people physical fitness (e.g., Stephen Hawking is active both in public life and science). Widely available instruments: mobile phone, replacing the camera placed on the patient's head, are supporting the execution of basic activities, such as reading, character recognition, or orientation in space. Examples can be multiplied, but the key issue is an indication, that the possibility of using prostheses, is frequently the only way of living among others. Human has to interact with the environment in order to develop his cognitive system. The feedback of perception and action is a fundamental condition of any living organism functioning properly in the world.

We should think about purposes and consequences of the use of mind prostheses. The problem is old. In the Phaedrus, Plato warns of the danger of writing. Human should trust only his own memory. ${ }^{17}$ Thoughts and history need to be remembered. In the dialogue, Socrates cites the myth. Theuth, the Egyptian god, gave a gift of writing to king Thamus. The wise king refused the gift. Thamus argued that the writing allow people to replace the wisdom with the appearance of knowledge. If people start to rely on writing to preserve knowledge, their memories would fade. They would confuse the truth with its empty illusion. This way of thinking appears also today. Many older people show contempt for younger people using calculators to do simple calculations or using Wikipedia as a source of knowledge. Perhaps, the true knowledge is in a human head and the most important cognitive abilities do not need any prosthesis. Still, a great question remains: what would a human be today if it was not for using tools?

16 P. Bach-y-Rita, S.W. Kercel, Sensory substitution and the human-machine interface, "Trends in Cognitive Sciences" 7 (2003) 12, pp. 541-546.

17 Platon, Fajdros, tłum. W. Witwicki, Kęty 2002. 


\section{Summary}

\section{New technologies as prothesis of cognitive system}

The aim of the paper is to show the way in which human cognitive system uses external prostheses. Currently developed technologies provide human beings with tools that change their way of functioning in the environment, their understanding and the perspective from which they perceive the world. Modifying systems of thoughts, reasoning and modes of operation non-biological prostheses extend human cognitive system. A human being uses non-biological interfaces for processing information from the external world.

Keywords prothesis, cognitive system, tools, extended mind

\section{Bibliography}

Bach-y-Rita P., Kercel S. W., Sensory substitution and the human-machine interface, „Trends in Cognitive Sciences” 7 (2003) 12, pp. 541-546.

Bolter J. D., Człowiek Turinga: kultura Zachodu w wieku komputera, tłum. T. Goban-Klas, Warszawa 1990.

Clark A., Being there: putting brain, body, and world together again, Cambridge 1997.

Clark A., Natural-born cyborgs. Minds, technologies, and the future of human intelligence, New York 2004.

Cosmides L., Tooby J., Cognitive adaptations for social exchange, „The Adapted Mind" 1992, pp. 163-228.

Fodor J.A., Eksperci od wiazów. Język myśleński i jego semantyka, tłum. M. Gokieli, Warszawa 2001.

Nęcka E., Orzechowski J., Szymura B., Psychologia poznawcza, Warszawa 2013.

Platon, Fajdros, tłum. W. Witwicki, Kęty 2002.

Zyzik R., Emocje 2.0, http://www.granicenauki.pl/index.php/pl/granice-nauki/ umysl/436-emocje-20 (3.01.2014). 